\title{
Michel Houellebecq sous la loupe, études réunies par Murielle Lucie Clément et Sabine van Wesemael
}

\section{[chiara elefante]}

\section{(2) OpenEdition}

1 Journals

\section{Edizione digitale}

URL: http://journals.openedition.org/studifrancesi/8375

DOI: $10.4000 /$ studifrancesi.8375

ISSN: 2421-5856

\section{Editore}

Rosenberg \& Sellier

\section{Edizione cartacea}

Data di pubblicazione: 1 mai 2009

Paginazione: 210-211

ISSN: 0039-2944

\section{Notizia bibliografica digitale}

[chiara elefante], «Michel Houellebecq sous la loupe, études réunies par Murielle Lucie Clément et Sabine van Wesemael», Studi Francesi [Online], 157 (LIII | I) | 2009, online dal 30 novembre 2015, consultato il 11 janvier 2021. URL: http://journals.openedition.org/studifrancesi/8375 ; DOI: https:// doi.org/10.4000/studifrancesi.8375

Questo documento è stato generato automaticamente il 11 janvier 2021.

\section{(c) $($ ) $\odot$}

Studi Francesi è distribuita con Licenza Creative Commons Attribuzione - Non commerciale - Non opere derivate 4.0 Internazionale. 


\title{
Michel Houellebecq sous la loupe, études réunies par Murielle Lucie Clément et Sabine van Wesemael
}

\author{
[chiara elefante]
}

\section{NOTIZIA}

Michel Houellebecq sous la loupe, études réunies par Murielle Lucie CLÉMENT et Sabine van WESEMAEL, Amsterdam-New York, Rodopi («Faux titre», 304), 2007, pp. 405.

1 Gli studi raccolti in questo volume hanno il compito, secondo le parole delle curatrici, di colmare la distanza ancora esistente tra l'opera di M. Houelle-becq, più che apprezzata dal grande pubblico, e il mondo accademico. All'interno del volume vengono studiate le possibili influenze, sull'opera dell'autore, di scrittori o filosofi che lo hanno preceduto, nonché i molteplici legami di intertestualità con opere contemporanee. Jacob CARLSON (Écriture Houelle-becquienne, écriture ménippéenne?, pp. 19-30) propone di avvicinare la scrittura di Houelle-becq alla tradizione della satira menippea. Murielle CLÉMENT (Michel Houelle-becq. Ascendances littéraires et intertextualités, pp. 93-107) stabilisce invece un parallelismo tra un frammento delle Particules élémentaires e un passo di Romeo e Giulietta di Shakespeare. Per ciò che concerne gli autori francesi del XIX e XX secolo, Bruno VIARD (Faut-il en rire ou en pleurer? Michel Houelle-becq du côté de Marcel Mauss et du côté de Balzac, pp. 31-42) esplora gli aspetti balzacchiani dell'opera di Houelle-becq, mentre Sandrine RABOSSEAU (Houelle-becq ou le renouveau du roman expérimental, pp. 43-51) ne analizza il discorso sociobiologique, che interpreta come un clin d'œil a Zola e al Naturalismo. Julia PRöLL (La Poésie urbaine de Michel Houelle-becq: sur les pas de Charles Baudelaire?, pp. 53-68) segnala l'influenza di Baudelaire sulla poesia di Houelle-becq, e sulla corrispondenza intima tra i due autori si concentra anche Elisabetta SIBILIO ("Je ne savais absolument rien de sa vie». Écrire l'autre: Houelle-becq, Lovecraft et..., pp. 81-91). Simon ST-ONGE (De l'esthétique Houelle-becquienne, 
pp. 69-80) identifica invece nel carattere ibrido dei testi di Houelle-becq un elemento di vicinanza con Lautréamont. Roger CÉLESTIN (Du style, du plat, de Proust et de Houelle-becq, pp. 345-356) confronta l'opera romanzesca di Houelle- becq con quella di Proust e constata, in particolare nella concezione dello stile, una profonda divergenza. JeanLouis CORNILLE (Extension du domaine de la Littérature ou 'J'ai Lu' 'L'Étranger", pp. 133-143) considera l'opera di Houelle-becq legata a quella di Kafka, Ionesco, ma soprattutto Camus. Tra le possibili fonti, John MCCANn (La Lutte des discours: "Plateforme" de Michel Houelle-becq, pp. 367-377) cita anche l'importanza di prodotti televisivi e guide turistiche. Walter WAGNER (Le Bonheur du néant: une lecture schopenhauerienne de Houelle-becq, pp. 109-122) e Floriane PLACE-VERGHNES (Houelle-becq/Schopenhauer: souffrance et désir gigognes, pp. 123-132) evocano poi la figura di Schopenhauer come uno dei principali maestri spirituali di Houelle-becq, in particolare per l'importanza del desiderio sessuale in quanto espressione immediata di volontà.

2 Si passa poi all'analisi dell' influenza di Houelle- becq sull'attuale paesaggio letterario francese: Alain-Philippe DURAND ( Pascal Bruckner et Michel Houelle-becq. Deux transécrivains au milieu du monde, pp. 157-167) vede nell'opera di Pascal Bruckner una profonda vicinanza a quella di Houelle-becq, mentre Nathalie DuMAS (Lutte à 99F: la vie sexuelle selon Michel $H$. et son extension à Frédéric B., pp. 215-225) presenta un'analisi contrastiva di Extension du domaine de la lutte e di $99 \mathrm{~F}$ di Beigbeder. Sabine van WESEMAEL (La Peur de l'émasculation, pp. 169-183) esamina invece il romanzo Existence di Éric Reinhardt e si chiede se il legame tra sessualità e nevrosi sul quale entrambi gli autori insistono sia un omaggio alle teorie di Freud o non ne rappresenti piuttosto una satira feroce. Sul legame tra Houelle-becq e le teorie psicanalitiche, questa volta anche di Lacan, si concentra lo studio di Anne-Marie PICARD-DriLLIEN (No Future! Le désistement mélancolique de Michel Houelle-becq, pp. 185-199).

3 Ampio spazio viene poi lasciato agli studi sull'importanza della sessualità e del voyeurismo: secondo Neli DoBReVA (Figures et transformations du corps féminin (en asexué) dans "Les Particules élémentaires" de Michel Houelle-becq, pp. 227-239) nella scrittura di Houelle-becq si assiste a una strumentalizzazione del corpo, mentre secondo Mads Anders BAGGESGAARD (Le Corps en vue - trois images du corps chez Michel Houelle-becq, pp. 241-252) l'utilizzo dell'immagine pornografica è soprattutto strumento per esplorare $\mathrm{i}$ limiti e le possibilità della descrizione corporea. Sara KIPPUR (Le Voyeurisme impossible chez Houelle-becq: l'œil, le regard, et la disparition de l'humanité, pp. 253-264) insiste sul voyeurismo come metafora dell'impossibilità di vedere, mentre Christiaan van TREECK (L'Image des Allemand(e)s dans l'œuvre narrative de Houelle-becq, pp. 315-331) analizza l'immagine stereotipica e i comportamenti sessuali dei personaggi tedeschi nei romanzi dell'autore.

Viene poi analizzata l'estetica nichilista dell'opera di Houelle-becq sia dal punto di vista contenutistico che strutturale: se per Frédéric SAYER (La Transformation de symboles du mal en signes du vide chez Michel Houelle-becq et Bret Easton Ellis, pp. 145-155) le opere dell'autore, con il loro sentimento del nulla e del vuoto, hanno un forte impatto sociale, per Daniel LAFOREST (Mondialisation, espace et séparation chez Michel Houelle-becq, pp. 265-276) si può constatare una forte presenza del sentimento di angoscia depressiva che rinnega l'illusione postmoderna di un rapporto armonico con l'Altro, mentre per Patrick RoY (Une étrange lumière: Michel Houelle-becq ou la vision du poisson, pp. 333-344) il nichilismo rappresenta un elemento di forte innovatività. Olivier BESSARD-BANQUY (Le 
Degré zéro de l'écriture selon Houelle-becq, pp. 357-365), Vincent BRUYÈRE (Solitude de Houellebecq: à propos de l'économie d'une fable, pp. 379-391) e Sylvie LoIGNON ("Quoiqu'il ne pousse ni grands gestes ni grands cris», pp. 393-402) insistono poi sul carattere "interrogativo" del nichilismo di Houelle-becq, che porta alla creazione di un anti-mondo e di una nuova forma romanzesca. David Evans (Structure et suicide dans les "Poésies" de Michel Houellebecq, pp. 201-214) identifica il tema del nichilismo nella forte alternanza che i versi dell'Autore presentano tra forme metriche tradizionali e forme libere.

Alla nuova visione del viaggio e del turismo nell'opera di Houelle-becq sono infine dedicati i saggi di Maud GRANGER REMY (Le Tourisme est un potshumanisme. Autour de "Plateforme", pp. 277-286), Julie DelORME (Du guide touristique au roman. "Plateforme" de Michel Houelle-becq, pp. 287-300) e Benjamin VERPOORT (Voyage au bout de l'Europe: "Lanzarote" de Michel Houelle-becq, pp. 301-314): nei tre studi viene analizzata nel dettaglio la metamorfosi dell'apparato romantico-realista associato al viaggio e la rappresentazione, nella finzione romanzesca, di un turismo che è ormai, a tutti gli effetti, fortemente segnato dall'aspetto economico e dalla globalizzazione. 